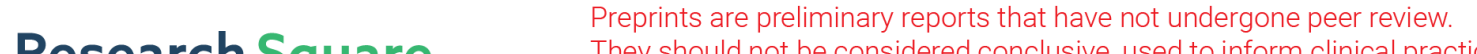 They should not be considered conclusive, used to inform clinical practice, or referenced by the media as validated information. \\ Degradation of Acid Red B by Manganese doped iron oxychloride and Permonosulfate: Performance and Inhomogeneous Activation Mechanism
}

\section{Rong Chen}

Suzhou University of Science and Technology

Dan Zhao ( $\square$ danny1972820@163.com )

Suzhou University of Science and Technology https://orcid.org/0000-0001-9348-3045

Yanmao Dong

Suzhou University of Science and Technology

Chengrun Cai

Suzhou University of Science and Technology

Yan Yuan

Suzhou University of Science and Technology

Zhili Li

Suzhou University of Science and Technology

\section{Research Article}

Keywords: Mn-FeOCl material, Permonosulfate (PMS), Acid red B (ARB), Sulfate radical (SO4·-)

Posted Date: August 17th, 2021

DOI: https://doi.org/10.21203/rs.3.rs-587174/v1

License: (c) (i) This work is licensed under a Creative Commons Attribution 4.0 International License.

Read Full License 


\title{
Degradation of Acid Red B by Manganese doped iron oxychloride and Permonosulfate: Performance and Inhomogeneous Activation Mechanism
}

\author{
Rong Chen ${ }^{1}$, Dan Zhao ${ }^{1 *}$, Yanmao Dong ${ }^{2}$, Chengrun Cai ${ }^{1}$, Yan Yuan ${ }^{2}$, Zhili Li ${ }^{1}$ \\ (1. School of Environmental Science and Engineering, Suzhou University of Science and \\ Technology, Suzhou, Jiangsu 215009, China;
}

2.School of Chemistry and Life Sciences, Suzhou University of Science and Technology, Suzhou, Jiangsu 215009, China)

Corresponding auther: Dan Zhao (E-mail: danny1972820@163.com. Tel:13915552787)

\begin{abstract}
Mn-FeOCl) was synthesized by partial pyrolysis method. The $\mathrm{Mn}-\mathrm{FeOCl}$ was used as heterogeneous catalyst to activate permonosulfate (PMS) for the degradation of azo dye acid red B(ARB) for the first time. The Mn-FeOCl was characterized by X-ray photoelectron spectroscopy (XPS), scanning electron microscopy (SEM), transmission electron microscopy (TEM) and X-ray diffraction spectroscopy (XRD). The effects of $\mathrm{Mn}-\mathrm{FeOCl}$ dosage, $\mathrm{PMS}$ concentration, initial $\mathrm{pH}$ value, $\mathrm{Cl}$ ion concentration and humic acid (HA) dosage on the degradation of ARB by Mn-FeOCl/PMS were investigated. Results showed that the ARB was degraded effectively by $\mathrm{Mn}-\mathrm{FeOCl} / \mathrm{PMS}$. The mineralization rate of ARB reached $42.5 \%$. As the $\mathrm{Mn}-\mathrm{FeOCl}$ dosage was $0.1 \mathrm{~g} / \mathrm{L}$, PMS concentration was $1 \mathrm{mmol} / \mathrm{L}$, and ARB concentration was $0.05 \mathrm{mmol} / \mathrm{L}$, the degradation rate of $A R B$ reached $99.4 \%$ in 30 minutes. With the increase of PMS dosage, $\mathrm{Mn}-\mathrm{FeOCl}$ dosage, $\mathrm{Cl}^{-}$ion concentration and initial $\mathrm{pH}$ value, the decolorization effect of ARB increased. The reaction mechanism was analyzed by free radical quenching experiment and XPS. The main active species were determined as $\cdot \mathrm{OH}$ and $\mathrm{SO}_{4} \cdot{ }^{-}$which generated by PMS activation. The $\mathrm{SO}_{4} \cdot{ }^{--}$was the main active species.
\end{abstract}

Keywords: Mn-FeOCl material; Permonosulfate (PMS); Acid red B (ARB); Sulfate radical $\left(\mathrm{SO}_{4} \cdot{ }^{-}\right)$

\section{Introduction}

Azo dyes that contain one or more azo bonds $(-\mathrm{N}=\mathrm{N}-)$ in their molecular structure (Robinson et al. 2001).It is widely used in various industries, including in textiles, food, leather, cosmetics and pharmaceuticals, according to statistics, the total output of dyes in the world is as high as $10000 t$, of which more than $15 \%$ are lost in the dyeing process (Ghanavatkar et al. 2021). The discharge of azo wastewater decreases the transparency and destroys the ornamental value of natural water. In addition, azo dyes have high chromaticity, high toxicity, complex composition and are difficult to be degraded (Zou et al. 2020) Meanwhile, the discharge of this wastewater also threatens ecosystem and human health because these compounds and their degradation products exhibit ecotoxicity. Thus, the removal and degradation of azo dyes have long received attention.

Advanced oxidation process (AOPs) is an efficient and inexpensive method for the treatment of refractory organic wastewater. AOPs can produce a large number of active free radicals, mainly hydroxyl radical $(\cdot \mathrm{OH})$ and sulfate radical $\left(\mathrm{SO}_{4} \cdot{ }^{-}\right)$. The Fenton reaction system based on $\cdot \mathrm{OH}$ has a narrow $\mathrm{pH}$ range $(\mathrm{pH}=2.5-3.5)$, and produces iron sludge, resulting in secondary pollution. Compared with $\cdot \mathrm{OH}, \mathrm{SO}_{4} \cdot{ }^{-}$has a higher REDOX potential (2.5V-3.1V) (Hao et al. 2014). It has high 
efficiency and oxidation selectivity for the degradation of pollutants containing unsaturated bonds. Longer half-life and wider application range of pH (Tugba et al. 2013; Yuan et al 2011); It can degrade contaminants and mineralize them or degrade them into small molecules. In addition, $\mathrm{SO}_{4}{ }^{-}$ can also be used as a disinfectant to disinfect bacteria (Wordofa et al. 2017). The main methods of producing $\mathrm{SO}_{4} \cdot-$ include activation of persulfate (PDS) and permonosulfate (PMS) by heat (Cao et al. 2021), alkali (Wei et al. 2021), ultraviolet (UV) (Asam et al. 2020), ultrasonic (Xu et al. 2020) and transition metal (Malik et al. 2016) Among them, transition metal activation cost is lower and more efficient. The asymmetric molecular structure of PMS is more easily activated by metals and their oxides than that of PDS (Ding et al. 2020). The commonly used transition metal catalysts include cobalt, copper, manganese, iron and materials containing one or more transition metal catalysts. Cobalt and copper as catalysts release toxic metal ions in the process of reaction, which will also cause environmental pollution and limit their practical application. However, Fe-based catalyst is a better choice because of its non-toxic and large storage capacity. Non-homogeneous Febased catalysts such as nanometer zero-valent iron (NZVI) (Chen et al. 2020), magnetic $\mathrm{Fe}_{3} \mathrm{O}_{4}(\mathrm{Xu}$ et al. 2021) and spinel ferrite $\left(\mathrm{CuFe}_{2} \mathrm{O}_{4}\right)$ (Ding et al. 2021) have been used to activate PMS and have good removal effect. Therefore, it is still necessary to explore new Fe-based PMS activators.

Iron oxychloride $(\mathrm{FeOCl})$ is a typical two-dimensional layered metal chloride oxide with high catalytic performance of heterogeneous catalyst. The $\mathrm{FeOCl}$ was used for the first time in heterogeneous Fenton reaction to catalyze the degradation of persistent organic matter in water (Yang et al. 2013). The decomposition of $\mathrm{FeOCl}$ can produce $\cdot \mathrm{OH}$ with high activity, researchers tried to combine $\mathrm{FeOCl}$ with non-metals such as reduced graphene oxide (rGO) (Zhang et al. 2018), silica $\left(\mathrm{SiO}_{2}\right)$ (Yang et al. 2016), and graphite-carbonitrogen compound $\left(\mathrm{g}-\mathrm{C}_{3} \mathrm{~N}_{4}\right)$ (Zhao et al. 2020), with remarkable results. In addition, metal doping can also greatly improve the degradation efficiency, such as Sn (Jiang et al. 2019), Ce (Zhang et al. 2019), Co (Tan et al. 2021) and other elements.

In this study, the cleaner $\mathrm{Mn}$ element doped $\mathrm{FeOCl}$ as heterogeneous catalyst ( $\mathrm{Mn}-\mathrm{FeOCl})$ heterogeneous Fenton catalyst was prepared by partial pyrolysis. Using azo dye acid red B(ARB) as the target pollutant, the activation of PMS by $\mathrm{Mn}-\mathrm{FeOCl}$ under different conditions was investigated. The main active species and reaction mechanism of Mn-FeOCl/PMS system for the degradation of ARB were revealed by free radical quenching and XPS experiments.

\section{Materials and methods}

\section{Chemicals and reagents}

Acid Red B (ARB) was purchased from Sinoptic Chemical Reagent Company (related parameters are shown in Table 1), perisulfate $\left(2 \mathrm{KHSO}_{5} \cdot \mathrm{KHSO}_{4} \cdot \mathrm{K}_{2} \mathrm{SO}_{4}, \mathrm{PMS}\right)$, ferric chloride $\left(\mathrm{FeCl}_{3} \cdot 6 \mathrm{H}_{2} \mathrm{O}\right)$, manganese chloride $\left(\mathrm{MnCl}_{2} \cdot 4 \mathrm{H}_{2} \mathrm{O}\right)$, sodium nitrite $\left(\mathrm{NaNO}_{2}\right)$, Sulphuric acid $\left(\mathrm{H}_{2} \mathrm{SO}_{4}\right)$, sodium hydroxide $(\mathrm{NaOH})$, sodium chloride $(\mathrm{NaCl})$, humic acid $(\mathrm{HA})$, methanol $\left(\mathrm{CH}_{3} \mathrm{OH}\right)$, tertbutanol $\left(\mathrm{C}_{4} \mathrm{H}_{9} \mathrm{OH}\right)$, acetone $\left(\mathrm{C}_{3} \mathrm{H}_{6} \mathrm{O}\right)$, sodium dihydrogen phosphate $\left(\mathrm{NaH}_{2} \mathrm{PO}_{4} \cdot 2 \mathrm{H}_{2} \mathrm{O}\right)$ and disodium hydrogen phosphate $\left(\mathrm{HNa}_{2} \mathrm{O}_{4} \mathrm{P} \cdot 7 \mathrm{H}_{2} \mathrm{O}\right)$ were all analytical pure. Ultra-pure water was used for the experiment. 


\begin{tabular}{ccccc}
\hline Molecular & $\begin{array}{c}\text { Constitutional } \\
\text { formula }\end{array}$ & $\begin{array}{c}\text { Molecular } \\
\text { weight }\end{array}$ & $\begin{array}{c}\lambda \\
\max / \mathrm{nm}\end{array}$ & Character \\
$\mathrm{C}_{20} \mathrm{H}_{12} \mathrm{~N}_{2} \mathrm{Na}_{2} \mathrm{~S}_{2} \mathrm{O}_{7}$ & 502.428 & 515 & $\begin{array}{c}\text { Azobenzene sulfonates, } \\
\text { anionic type }\end{array}$ \\
\hline
\end{tabular}

\section{Preparation of Mn-FeOCl}

The catalyst of $\mathrm{Mn}-\mathrm{FeOCl}$ was prepared according to one-pot method. Firstly, a mixture of 1.0 $\mathrm{g} \mathrm{FeCl} \cdot 6 \mathrm{H}_{2} \mathrm{O}$ and $0.2 \mathrm{~g} \mathrm{MnCl}_{2} \cdot 4 \mathrm{H}_{2} \mathrm{O}$ was dissolved in $0.8 \mathrm{~mL} \mathrm{H}_{2} \mathrm{O}$ in a porcelain crucible, and then sonicated for $10 \mathrm{~min}$. The crucible was subsequently placed in an oven at $50{ }^{\circ} \mathrm{C}$ for 10 hours to achieve coagulation. Following coagulation, the dried sample was sealed with nitrogen and the temperature was raised to $250^{\circ} \mathrm{C}$ at a rate of $1^{\circ} \mathrm{C} / \mathrm{min}$ and held for $60 \mathrm{~min}$ in a muffle furnace. After being naturally cooled to room temperature, the sample was ground to powder and washed with acetone subsequently by centrifuge. The collected sample was placed in a vacuum drying box at $60{ }^{\circ} \mathrm{C}$ for $8 \mathrm{~h}$ to finally obtain $\mathrm{Mn}-\mathrm{FeOCl}$ (Tan et al. 2021).

\section{Degradation experiment}

Accurately weigh a certain amount of $\mathrm{Mn}-\mathrm{FeOCl}$ into $100 \mathrm{~mL}$ of an acid red $\mathrm{B}(\mathrm{ARB})$ solution of a specific concentration, and sonicate it for 5minutes to make it uniformly dispersed. Use $0.01 \mathrm{~mol} / \mathrm{L} \mathrm{H}_{2} \mathrm{SO}_{4}$ and $\mathrm{NaOH}$ solutions to adjust $\mathrm{pH}$. Then magnetically stir $30 \mathrm{~min}$ to reach adsorption/desorption equilibrium. Adding PMS to start the reaction. Samples were taken at a predetermined time and quenched with $0.20 \mathrm{~mol} / \mathrm{L} \mathrm{NaNO}_{2}$ to stop the reaction. The absorbance of the remaining dyes was measured after the samples were filtered with a $0.45 \mu \mathrm{m}$ filter head. Two parallel reactions were set for each group.

The reaction solution was centrifuged, washed with pure water, repeated 3 times, and vacuum dried to obtain use $\mathrm{Mn}-\mathrm{FeOCl}$. The above steps were repeated 3 times to check its repeatability and stability.

\section{Analytical method}

The morphology of the materials was characterized by Quanta FEG 250 scanning electron microscope (SEM-EDS). The crystal structure of the catalyst was analyzed by Bruker D8Adwance X-ray diffraction (XRD) in Germany. Thermofisher X-ray photoelectron spectroscopy (XPS) was used to detect the element valence states before and after the use of the catalyst.PHS-3C type $\mathrm{pH}$ meter to measure the $\mathrm{pH}$ of the solution; The concentration of acid red $\mathrm{B}$ was quantified on a UVvis spectrophotometer (Mapada UV 1600(PC)) by monitoring the absorbance at the maximum wavelength of $515 \mathrm{~nm}$, Total organic carbon (TOC) measurement was carried out by a Shimazu TOC analyzer (TOC-LCPH, Shimazu, Japan). The electron spin resonance (EPR) spectrometer (JEOLFA200, Japan) was applied to measure $\mathrm{SO}_{4} \cdot-$ by using 5, 5-2-methyl-1-pyrroline-N-oxide (DMPO) as the radical spin trapping reagent. The removal efficiency was measured according to (Eq. (1))

$$
\text { Removal efficiency }(\%)=\left(C-C_{0}\right) / C_{0} \times 100 \%
$$

Where $\mathrm{C}_{0}$ and $\mathrm{C}$ represent the initial and final concentrations of pollutants 


\section{Result and discussion}

\section{Characterization}

Fig. 1 shows the SEM, TEM and EDS images of Mn-FeOCl. As displayed from the SEM results in Fig. 1(a-c), the Mn-FeOCl catalyst has a rectangular parallelepiped configuration, which belongs to a typical orthorhombic crystal system, and its obvious lamellar structure can be seen,

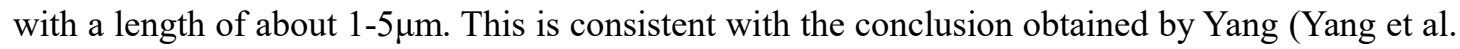
2016). Such a lamella structure effectively expands the specific surface area of the catalyst, which is beneficial to the contact between the catalyst and the pollutants. On the other hand, it increases the number of active sites of the catalyst and increases the output of free radicals. The TEM results Fig. 1(d-f) furtherly showed the same lamella morphology, with tight bonding between layers, neat edges, and a thickness of about 30nm, indicated the surface stripe morphology. To explore the existence of Mn element, the corresponding EDS characterization was analyzed. Results indicated that $\mathrm{Mn}, \mathrm{Fe}, \mathrm{O}$ and $\mathrm{Cl}$ were all present catalyst from EDS spectrum Fig. 1(g-j) and the mole ratio of the four elements were determined to be $6.6 \%, 41.2 \%, 19.5 \%$ and $32.6 \%$, respectively. Furthermore, EDS mapping results Fig. 1(k) revealed that $\mathrm{Mn}, \mathrm{Fe}, \mathrm{O}$ and $\mathrm{Cl}$ were uniform distribution. It furtherly indicated that $\mathrm{Mn}$ was successfully doped in the newly prepared material. Fig. 2 is a schematic diagram of the structure of $\mathrm{Mn}-\mathrm{FeOCl}$, in which the metal oxide and halogen layers are stacked in an orderly arrangement to form a $\mathrm{FeOCl}$ structure.
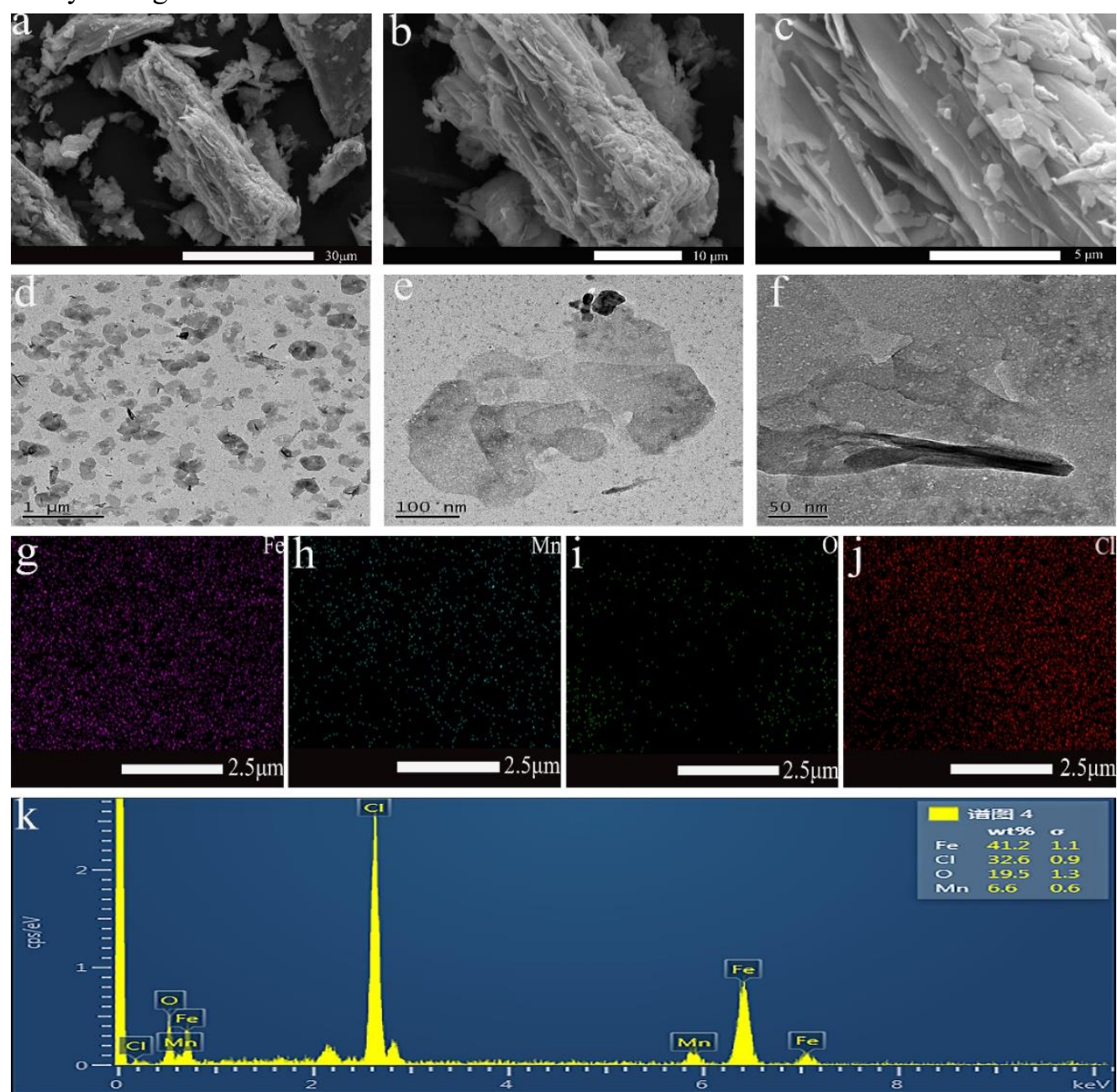

Fig. 1. (a-c) SEM image; (d-f) TEM image; (g-k) EDS image 


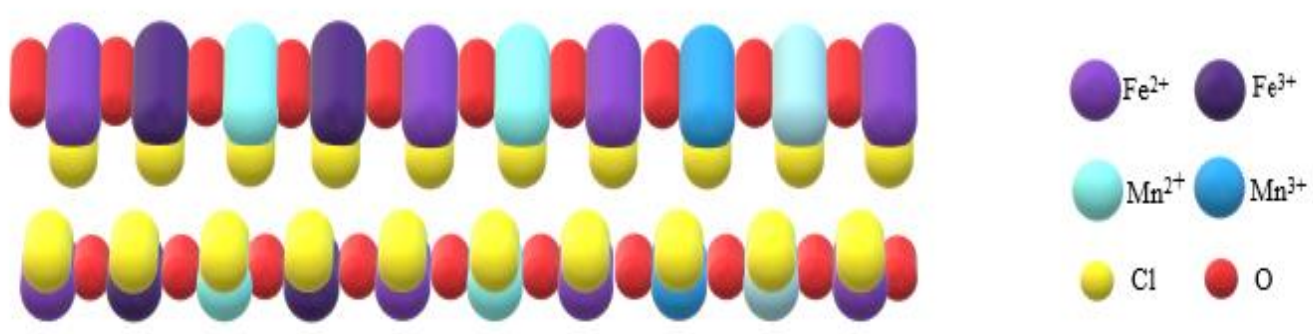

Fig. 2. Schematic diagram of $\mathrm{Mn}-\mathrm{FeOCl}$ structure

The XRD patterns Fig. 3(a) of the $\mathrm{Mn}-\mathrm{FeOCl}$ material is shown in the figure. It can be seen from the figure that the diffraction peaks of the synthetic material appear at $2 \theta=11.5 \%, 26.05 \%$, $35.48 \%$ and $38.1 \%$, respectively, corresponding to the $\mathrm{FeOCl}(010),(110),(021),(111)$ crystal plane (Dai et al. 2002), basically the same as pure FeOCl crystal (JCPDS No. 24-1005). The crystal structure of $\mathrm{Mn}-\mathrm{FeOCl}$ is proved, and the result shows that the prepared material contains rich unsaturated atom oxygen bridge structure ([Fe-O-Fe $]^{4+}$ ) and van der Waals layer (Chen et al. 2017); among them, the diffraction peak at $11.5 \%$ The strength is the highest. It is concluded that the main crystal face index of the catalyst produced this time is $(010)$. The calculated unit cell constants are: $\mathrm{a}=3.77596 \AA, \mathrm{b}=7.9099 \AA, \mathrm{c}=3.30133 \AA$, which are consistent with the standard card. The crystallinity calculated by the full spectrum fitting is $88.64 \%$, the crystallinity is high, and the crystal form is complete. Interestingly, the doped $\mathrm{Mn}$ hardly altered the lattice structure of $\mathrm{FeOCl}$, which may probably lie in the partly replacement of $\mathrm{Fe}$ by $\mathrm{Mn}$ in the lattice.

(a)

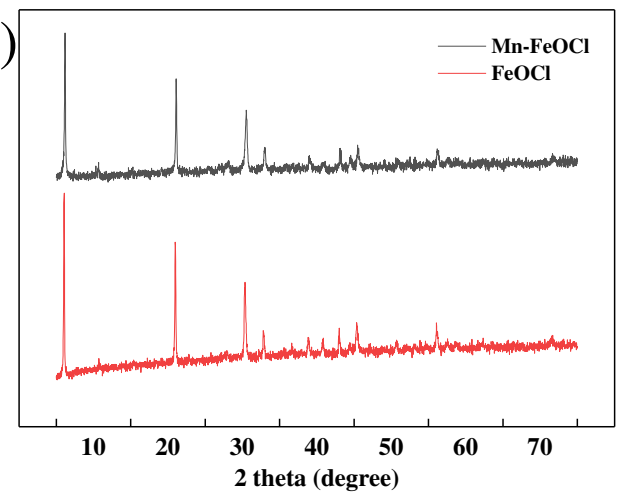

(c)

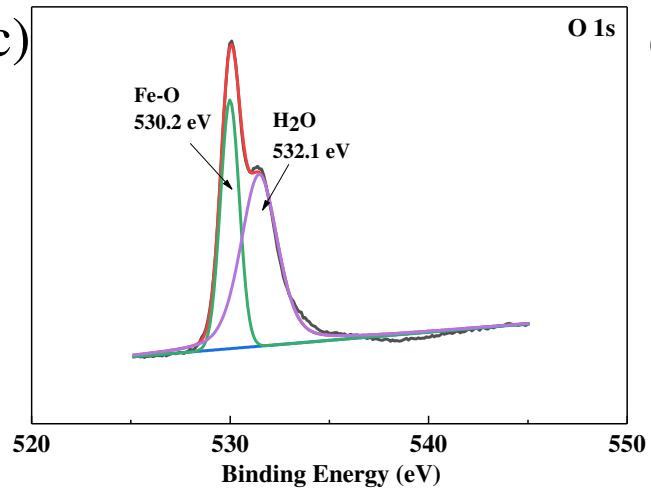

(b)

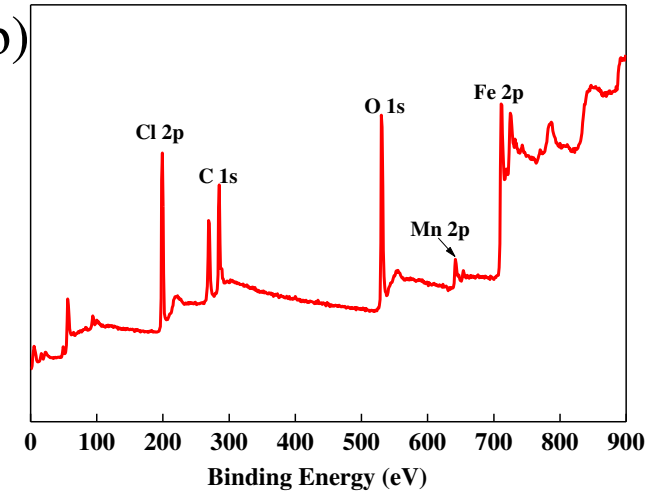

(d)

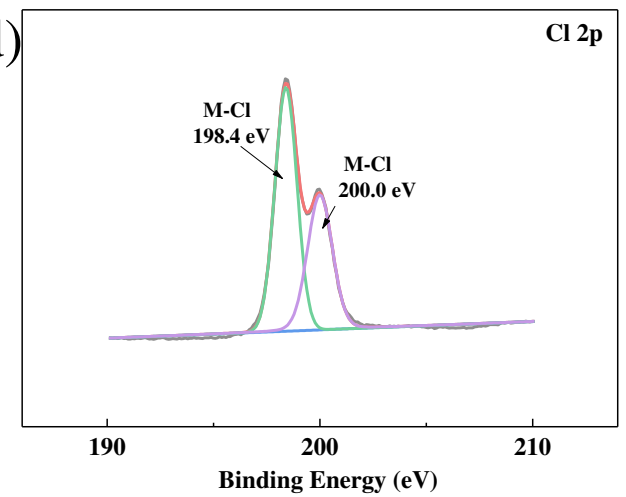

Fig. 3 (a) XRD image; (b) XPS spectra of Mn-FeOCl; (c) O element XPS image; (d) Cl element XPS image.

Fig. 3(b) is the XPS full spectrum of Mn-FeOCl material. It is clearly found that there are four 
elements $\mathrm{Fe}, \mathrm{Mn}, \mathrm{O}, \mathrm{Cl}$ and $\mathrm{C}$, and the binding energy of $\mathrm{Mn} 2 \mathrm{p}, \mathrm{Fe} 2 \mathrm{p}, \mathrm{O}$ 1s and $\mathrm{Cl} 2 \mathrm{p}$ element corresponding to $710.91 \mathrm{eV}, 652.63 \mathrm{eV}, 530.31 \mathrm{eV}$ and $201.54 \mathrm{eV}$ separately. According to the precious literatures (Sun et al. 2020). Among them, C 1s is the externally contaminated carbon, which is used as the reference peak for calibration. Fig. 3(c) shows that the binding energy of $\mathrm{O} 1 \mathrm{~s}$ are $531.8 \mathrm{eVand} 532.5 \mathrm{eV}$, which correspond to the Fe-O bond and $\mathrm{H}_{2} \mathrm{O}$ molecules adsorbed on the catalyst surface, respectively (Cao et al. 2021). Fig. 3(d) shows that the binding energy of the Fe-Cl bond is $198.4 \mathrm{eV}$ and $200.0 \mathrm{eV}$ ( $\mathrm{Zhu}$ et al. 2016). The XPS results further confirm the bonding mode of atoms and combined form.

\section{The effect of ARB degradation under different reaction systems}

In order to study the catalytic performance of $\mathrm{Mn}-\mathrm{FeOCl}$, different reaction systems were set up for PMS catalytic performance. The results are shown in Fig. 4. As only $\mathrm{Mn}-\mathrm{FeOCl}$ material is added to the system, the concentration of ARB is basically unchanged within 30 minutes, indicating that $\mathrm{Mn}-\mathrm{FeOCl}$ alone has no oxidation or adsorption effect on ARB; within 30 minutes, less than $3 \%$ removal in the presence of PMS alone, indicating that PMS alone has a poor ability to oxidize organic matter. This result is consistent with the conjecture that PMS alone has limited ability to oxidize pollutants (Xu et al. 2015). Nevertheless, $\mathrm{FeOCl} / \mathrm{PMS}$ system attained significantly improvement on ARB degradation, indicating the PMS activation induced by $\mathrm{FeOCl}(\mathrm{Qu}$ et al. 2019) Respectively, as $0.1 \mathrm{~g} / \mathrm{L} \mathrm{Mn}-\mathrm{FeOCl}$ and $1 \mathrm{mmol} / \mathrm{L}$ PMS were added at the same time, the ARB removal rate reached $99.4 \%$ within 30 minutes, and the effect was significant. Compared to $\mathrm{FeOCl} / \mathrm{PMS}$ system, Mn-FeOCl/PMS system shorten the completely ARB degradation and improved the removal efficiency. The result evidenced PMS has an asymmetric structure and is easily activated by $\mathrm{Mn}-\mathrm{FeOCl}$ materials, resulting in strong Oxidizing free radicals (Guan et al. 2013), thereby improving the degradation efficiency.

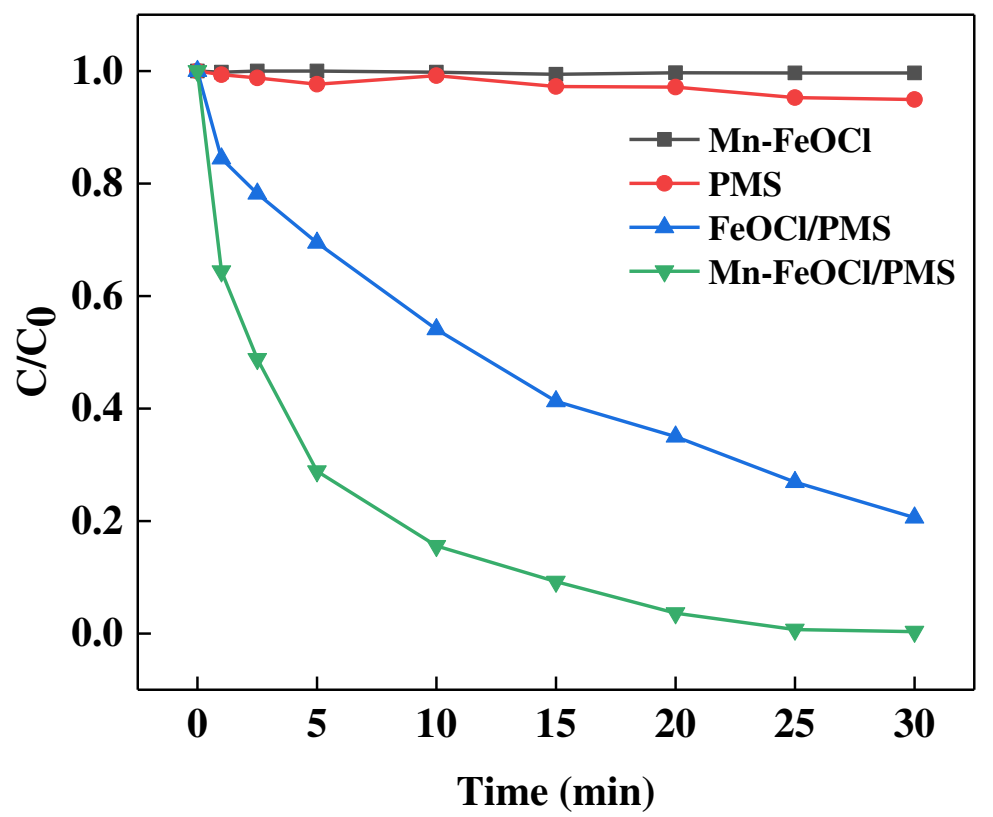

Fig.4. Degradation effect of Acid Red B in different systems. (Experimental conditions: initial ARB concentration $=0.05 \mathrm{mmol} / \mathrm{L}, \mathrm{FeOCl}=0.10 \mathrm{~g} / \mathrm{L}, \mathrm{Mn}-\mathrm{FeOCl}=0.10 \mathrm{~g} / \mathrm{L}, \mathrm{PMS}$ concentration $=1 \mathrm{mmol} / \mathrm{L}, \mathrm{pH}=7.0$, $\left.\mathrm{T}=25^{\circ} \mathrm{C}\right)$

\section{Effect of Mn-FeOCl dosage on the degradation of ARB}

The dosage of the catalyst is the key factor of the heterogeneous Fenton system. Keep the 
dosage ratio of PMS and ARB at 20:1, change the dosage of $\mathrm{Mn}-\mathrm{FeOCl}$ material to explore its influence on the ARB degradation experiment. The experimental results are shown in Fig. 5(a) and the corresponding kinetic curves of different $\mathrm{Mn}-\mathrm{FeOCl}$ dosages in $\mathrm{Mn}-\mathrm{FeOCl} / \mathrm{PMS}$ systems are shown in Fig.5(b).

With the increase of the catalyst dosage, the degradation rate of ARB is increasing. As the catalyst dosage increases from $0.03 \mathrm{~g} / \mathrm{L}$ to $0.2 \mathrm{~g} / \mathrm{L}$, after 30 minutes of reaction, the degradation rate of ARB increases from $92.5 \%$ to $99.4 \%$. The first-order rate constant is positively correlated with the dosage of the material. This is because the catalyst has an activation effect on PMS. As the dosage increases, $\mathrm{Mn}-\mathrm{FeOCl}$ provides More active sites are generated, thereby generating more free radicals and improving the degradation efficiency of ARB (Wang et al. 2017).

\section{Effect of PMS dosage on the degradation of ARB}

The degradation of ABR in Mn-FeOCl/PMS system with different PMS doses was investigated and shown in Fig. 5(c-d). The figure shows that as the concentration of PMS increases from $0.5 \mathrm{mmol} / \mathrm{L}$ to $1 \mathrm{mmol} / \mathrm{L}$, after 30 minutes of reaction, the degradation rate of ARB increases from $92 \%$ to $99.5 \%$. If the concentration of PMS continues to increase, the degradation rate of ARB changes little. This is because as the dosage of PMS increases, the free radicals generated by Mn$\mathrm{FeOCl}$ catalyst activation PMS increase, which speeds up the reaction. However, the active sites that the catalyst can provide are limited, and the PMS concentration is too high. The quenching reaction (Ding et al. 2013; Do et al. 2010) (Eq (2), Eq. (3)) occurs so that the degradation rate cannot be further improved.

$$
\begin{gathered}
\mathrm{HSO}_{5^{-}}+\mathrm{SO}_{4}^{-} \rightarrow \mathrm{SO}_{4}^{2-}+\mathrm{SO}_{5}^{-} \cdot+\mathrm{H}^{-} \\
\mathrm{HSO}_{5}^{-}+\cdot \mathrm{OH} \rightarrow \mathrm{SO}_{5}^{-} \cdot+\mathrm{H}_{2} \mathrm{O}
\end{gathered}
$$

\section{Effect of initial pH on the degradation of ARB}

Generally speaking, the influence of the initial $\mathrm{pH}$ value is usually related to the zeta potential of the catalyst (Tan et al. 2014); the pHpzc (pH at the point of zero charge) of $\mathrm{Mn}-\mathrm{FeOCl}$ measured by mass titration is about 6.3, therefore, keep the concentration of ARB, Mn-FeOCl, and PMS at different levels. To explore the effect of different initial $\mathrm{pH}$ values on the degradation of ARB, the results are shown in Fig. 5(e-f). As pH=3, the degradation efficiency of ARB for 30 minutes is only $28.2 \%$, indicating that the degradation effect of the system is poor under acidic conditions. The possible reason is that as $\mathrm{pH}<\mathrm{pHpzc}$, the surface of the material is positively charged, and under acidic conditions, there is a large amount of $\mathrm{H}^{+}$, which makes $\mathrm{H}^{+}$combine with the $\mathrm{O}-\mathrm{O}$ bond in the $\mathrm{HSO}_{5}{ }^{-}$group to form a hydrogen bond, which prevents the reaction of PMS with the catalyst and reduces ARB removal rate (Huang et al. 2021, Wang et al. 2008). With the gradual increase of $\mathrm{pH}$, the degradation rate of ARB also continues to increase. As the $\mathrm{pH}$ rises from 5 to 9 , the degradation rate of $\mathrm{ARB}$ rises from $77.8 \%$ to $99.5 \%$. Although the degradation effect of $\mathrm{pH}=7$ and $\mathrm{pH}=9$ is not much different, the reaction rate is significantly faster as $\mathrm{pH}=9$. This is because under alkaline conditions, PMS will be activated by alkali, forming a metal-OH complex in the $\mathrm{Mn}-\mathrm{FeOCl}$ material, and at a higher $\mathrm{pH}$ can accelerate the production of $\mathrm{SO}_{4} \cdot{ }^{-}$and accelerate the degradation of $\mathrm{ARB}$ (Guan et al. 2011). 

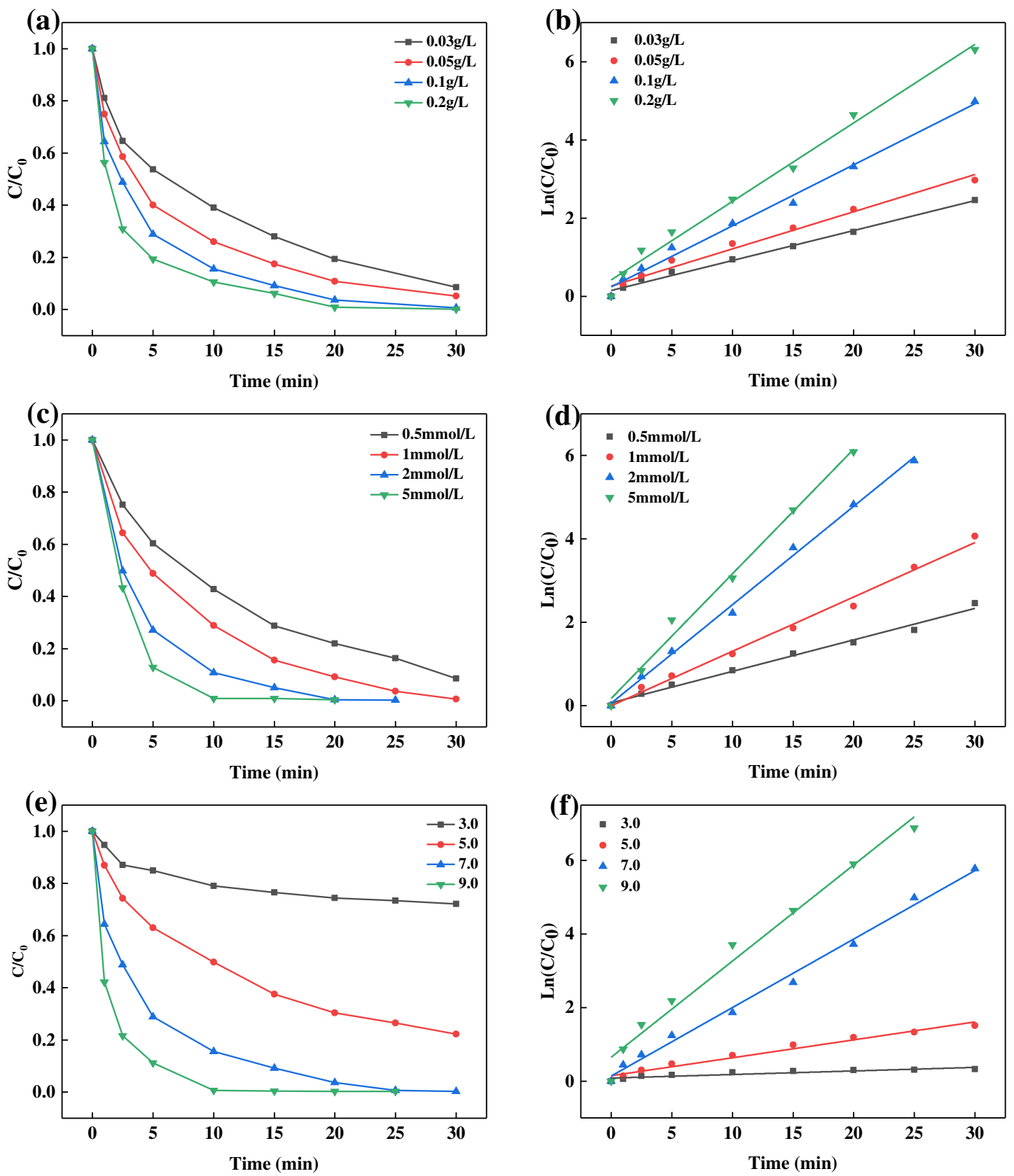

Fig. 5.the effect of catalyst dosage(a) and kinetic curves(b) on ARB degradation; the effect of PMS concentration (c) and kinetic curves(d); the effect of initial $\mathrm{pH}(\mathrm{e})$ and kinetic curves(f) on ARB degradation;

(Experimental conditions: initial ARB concentration $=0.05 \mathrm{mmol} / \mathrm{L}, \mathrm{Mn}-\mathrm{FeOCl}=0.10 \mathrm{~g} / \mathrm{L}, \mathrm{PMS}$ concentration

$\left.=1 \mathrm{mmol} / \mathrm{L}, \mathrm{pH}=7.0, \mathrm{~T}=25^{\circ} \mathrm{C}\right)$

Effect of concentration of $\mathrm{Cl}^{-}$on the degradation of ARB

Printing and dyeing wastewater generally contains a relatively high concentration of $\mathrm{NaCl}$, with a mass fraction of $15 \%-20 \%$; and the influence of $\mathrm{Cl}^{-}$on the reaction system is also very important. It can be seen from Fig. 6(a) that as the dosage increases, the reaction speed increases. At higher concentrations, $\mathrm{Cl}^{-}$can significantly accelerate the oxidation ability of the $\mathrm{Mn}$ $\mathrm{FeOCl} / \mathrm{PMS}$ system, which is similar to the predecessors in the presence of $\mathrm{Cl}^{-}$The research results 
of the degradation of pollutants by the $\mathrm{Mn}^{2+} / \mathrm{PMS}$ system are consistent (Wang et al. 2011) According to the Fig.6(b), the first-order rate constant increases linearly with the increase of $\mathrm{Cl}^{-}$. This may be due to the reaction of $\mathrm{Cl}^{-}$and $\mathrm{HSO}_{5}{ }^{-}$to form $\mathrm{HClO}$ and $\mathrm{Cl}_{2}$ (Eq. (4)-Eq. (9)) (Zhang et al. 2018; Huang et al.2017). HClO acts as a strong oxidant and has a good decolorization effect on azo dyes, thus accelerating the degradation of ARB.

$$
\begin{gathered}
\mathrm{HSO}_{5}{ }^{-}+\mathrm{Cl}^{-} \rightarrow \mathrm{SO}_{4}{ }^{2-}+\mathrm{HOCl} \\
\mathrm{SO}_{4}{ }^{-}+\mathrm{Cl}^{-} \rightarrow \mathrm{SO}_{4}{ }^{2-}+\mathrm{Cl} \cdot \\
\mathrm{Cl} \cdot+\mathrm{Cl}^{-} \rightarrow \mathrm{Cl}_{2}^{-} \\
\mathrm{Cl}_{2}{ }^{-}+\mathrm{Cl}_{2}^{-} \cdot \rightarrow \mathrm{Cl}_{2}+2 \mathrm{Cl}^{-} \\
\mathrm{Cl}_{2}{ }^{-}+\mathrm{Cl}^{-} \rightarrow \mathrm{Cl}_{2}+\mathrm{Cl}^{-} \\
\mathrm{Cl}_{2}+\mathrm{H}_{2} \mathrm{O} \rightarrow \mathrm{HOCl}
\end{gathered}
$$

\section{Effect of humic acid on the degradation of ARB}

The actual production wastewater containing natural organic matter (NOM) will also affect the reaction process. The addition of humic acid (HA) to the reaction system simulates the degradation ability of the Mn-FeOCl/PMS system on the ARB in the actual water body. As the Fig.6(c-d) shown that the dosage of HA is $10,20,50 \mathrm{mg} / \mathrm{L}$, the degradation rate of ARB within 30 minutes is $95.2 \%$, $90.8 \%$, and $68.4 \%$, respectively, which is inhibited. The analysis may be because HA consumes the reaction system. Free radicals, thereby inhibiting the degradation of ARB (Latifoglu et al. 2003). However, the content of NOM in natural waters is generally below $20 \mathrm{mg} / \mathrm{L}$, and its impact on the $\mathrm{Mn}-\mathrm{FeOCl} / \mathrm{PMS}$ system is also relatively limited.
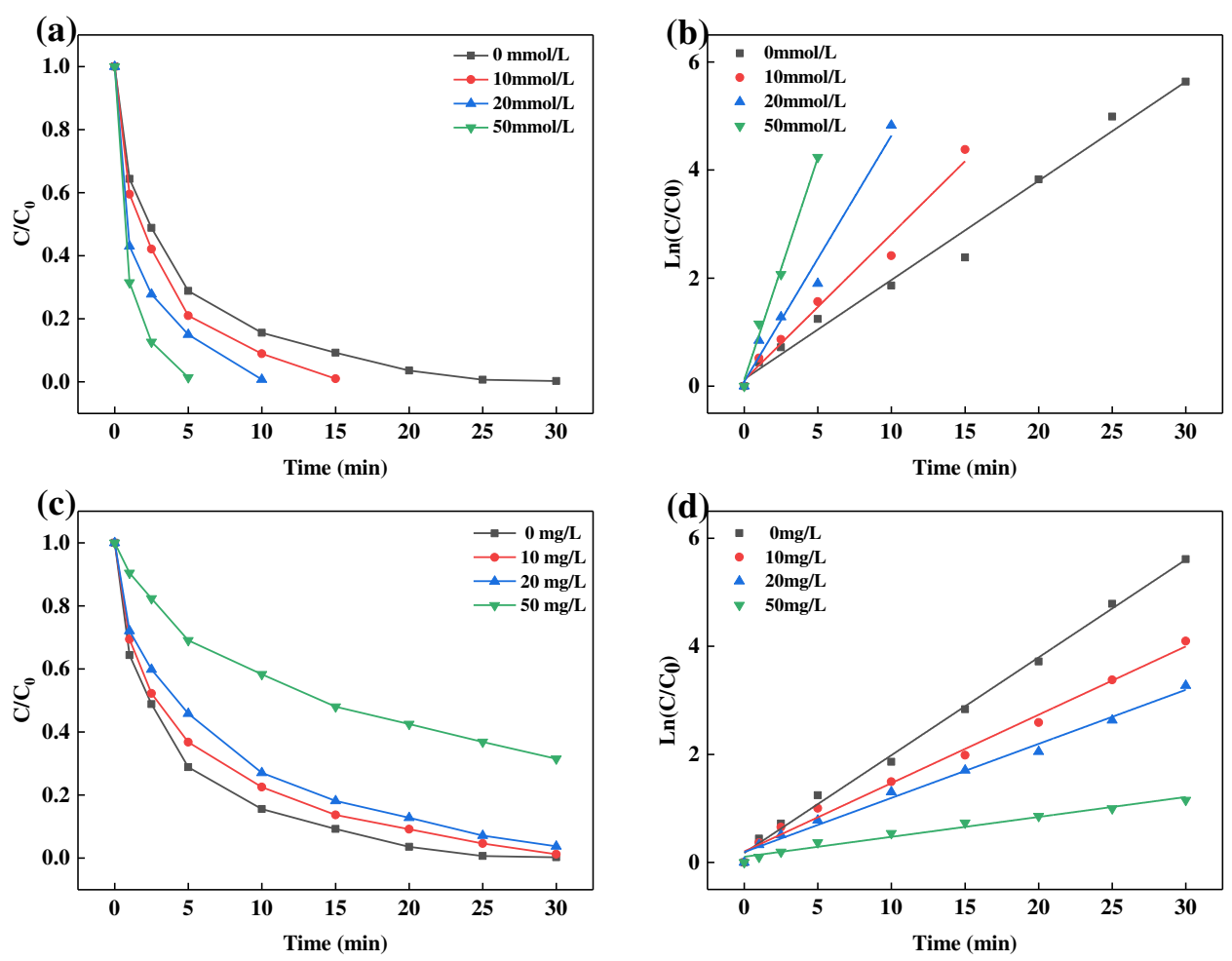

Fig.6. the effect of $\mathrm{Cl}$ iron concentration(a) and kinetic curves(b) on ARB degradation; the effect of human acid (HA) dosage(c) and kinetic curves(d); (Experimental conditions: initial ARB concentration=0.05mmol/L, Mn- 
In order to investigate the reaction mechanism of ARB degradation by Mn-FeOCl/PMS system, a free radical quenching experiment was carried out. According to reports, the transition metal activated PMS mainly produces $\cdot \mathrm{OH}$ and $\mathrm{SO}_{4} \cdot{ }^{-}$; methanol $(\mathrm{MeOH})$ and tert-butanol (TBA) are selected as a quencher to identify the main active species in the system (Buxton et al. 1988) $\mathrm{MeOH}$ has higher reaction rates for $\cdot \mathrm{OH}$ and $\mathrm{SO}_{4}{ }^{-}$, , respectively $(1.2 \sim 2.8) \times 10^{9} \mathrm{~mol}^{-1} \cdot \mathrm{s}^{-1}$ and $(1.6 \sim 7.7) \times 10^{7}$ $\mathrm{mol}^{-1} \cdot \mathrm{s}^{-1}$, which can be used for Quenching $\cdot \mathrm{OH}$ and $\mathrm{SO}_{4} \cdot-$; while the reaction rate of TBA to $\mathrm{SO}_{4} \cdot-$ is only $(4.0 \sim 9.1) \times 10^{5} \mathrm{~mol}^{-1} \cdot \mathrm{s}^{-1}$, which is much lower than that with $\cdot \mathrm{OH}(3.8 \sim 7.6) \times 10^{8} \mathrm{~mol}^{-1} \cdot \mathrm{s}^{-1}$, so it is often used to quench the identification of $\cdot \mathrm{OH}$ in the reaction. Fig. 7(a) shows the effect of two different quenchers on the degradation of ARB. As the dosage of TBA is 50 and $500 \mathrm{mmol} / \mathrm{L}$, the removal efficiency of ARB drops to $84.15 \%$ and $75.78 \%$ after 30 minutes of reaction. The results show that $\cdot \mathrm{OH}$ has a certain effect on the degradation of $\mathrm{ARB}$. As the dosage of $\mathrm{MeOH}$ was 50 and $500 \mathrm{mmol} / \mathrm{L}$, the removal rate of ARB after 30 minutes of reaction was $66.8 \%$ and $54.8 \%$. The inhibitory effect is more obvious, which indicates that both $\cdot \mathrm{OH}$ and $\mathrm{SO}_{4} \cdot^{-}$exist in the Mn$\mathrm{FeOCl} / \mathrm{PMS}$ system, and DMPO is used as a free radical trapping agent, and the electron spin resonance paramagnetic spectrometer (EPR) is used for the reaction process. As shown in Fig. 7(b), the characteristic signals of DMPO- $\mathrm{SO}_{4} \cdot{ }^{-}$adduct and DMPO- $-\mathrm{OH}$ adduct were detected (Wang et al. 2015), where $\mathrm{SO}_{4}{ }^{-}$- is the main free radical and the detection showed that a small amount of $\cdot \mathrm{OH}$ was present in the system at the same time, which was due to the reaction of $\mathrm{SO}_{4} \cdot{ }^{-}$with $\mathrm{OH}^{-}$in the solution to generate $\cdot \mathrm{OH}$ (Eq. (10)). EPR shows that $\mathrm{SO}_{4} \cdot{ }^{-}$dominates in the Mn-FeOCl/PMS system.

$$
\mathrm{SO}_{4}{ }^{-}+\mathrm{OH}^{-} \rightarrow \cdot \mathrm{OH}+\mathrm{SO}_{4}{ }^{2-}
$$
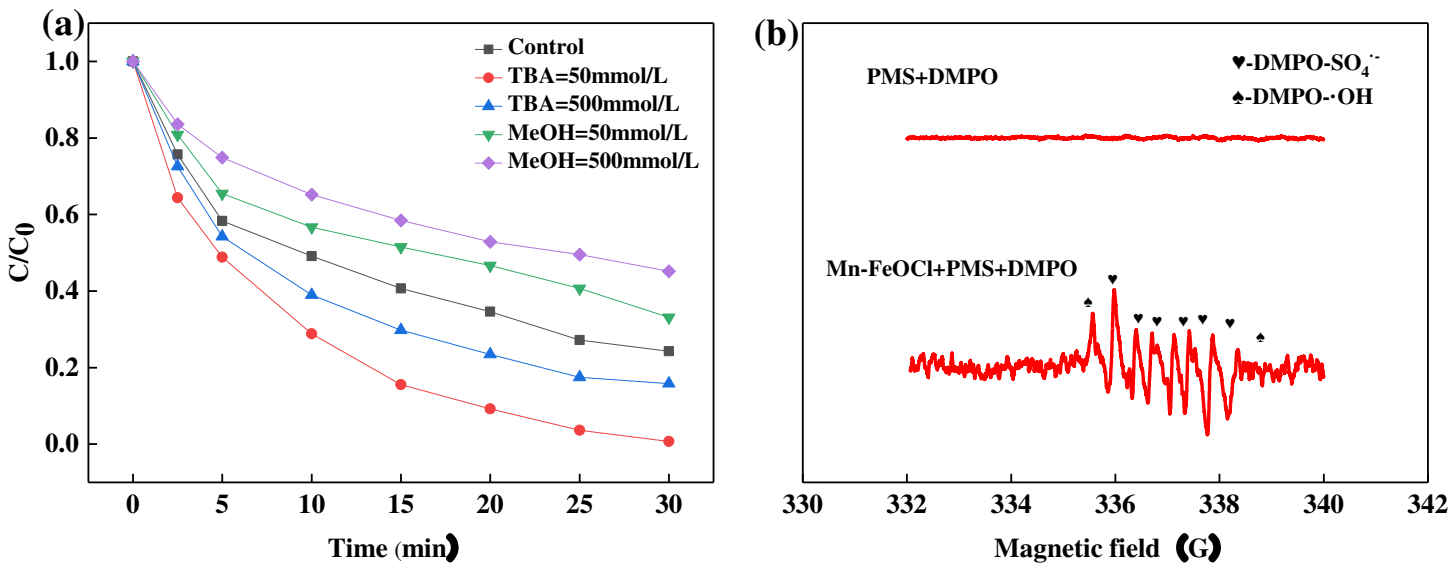

Fig. 7. (a)ARB degradation in the presence of different radical scavengers.; (b) EPR spectra in Mn-FeOCl/PMS system. (Experimental conditions: initial ARB concentration $=0.05 \mathrm{mmol} / \mathrm{L}, \mathrm{Mn}-\mathrm{FeOCl}=0.10 \mathrm{~g} / \mathrm{L}, \mathrm{PMS}$ concentration $=1 \mathrm{mmol} / \mathrm{L}, \mathrm{pH}=7.0, \mathrm{~T}=25^{\circ} \mathrm{C}$ )

\subsection{Possible mechanism}

In order to understand the changes of surface elements during the reaction, XPS was used to detect the element valences in $\mathrm{Mn}-\mathrm{FeOCl}$ before and after the reaction. The results are shown in Fig. 8 (a). The $\mathrm{Mn}-\mathrm{FeOCl}$ catalysts are at $711.5 \mathrm{eV}$ and $711.5 \mathrm{eV}$ and $724.9 \mathrm{eV}$ corresponds to $\mathrm{Fe} 2 \mathrm{p} 3 / 2$ and $\mathrm{Fe} 2 \mathrm{p} 1 / 2$ (Sun et al. 2018), and the corresponding satellite peaks are $718.8 \mathrm{eV}$ and $731.4 \mathrm{eV}$, respectively. Before the reaction, $\mathrm{Fe} 2 \mathrm{p}$ corresponds to $\mathrm{Fe}^{2+}$ and $\mathrm{Fe}^{3+}$ at $711.03 \mathrm{eV}$ and $713.9 \mathrm{eV}$, and its content is $70.2 \%$ and $\mathrm{Fe}^{3+}$ is $29.8 \%$. After activating PMS to degrade $\mathrm{ARB}$, the content of $\mathrm{Fe}^{2+}$ 
and $\mathrm{Fe}^{3+}$ are $56.6 \%$ and $43.4 \%$ respectively. During the reaction, the $\mathrm{Fe}^{3+}$ content increased by $13.6 \%$, which is consistent with the previous study by previous researchers. (Chen et al. 2013; Qu et al.2020). The significant change in the valence state indicates the existence of electron transfer during the reaction. In addition, the spectrum of Mn $2 p$ as shown in Fig.8(b) shows different peak shapes, which may be due to the low load and high background value (Ma et al. 2019). It can be observed that the peak value of $\mathrm{Mn} 2 \mathrm{p}$ is significantly reduced after the reaction, and it can be seen that $\mathrm{Mn}$ is also involved in the reaction.

(a)

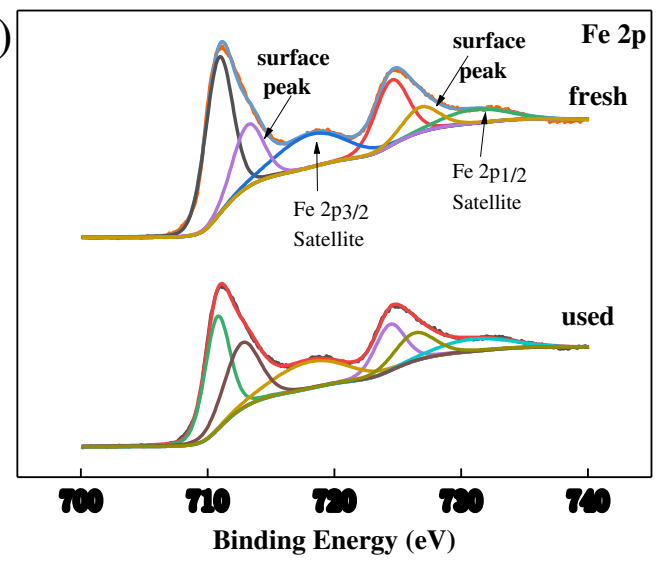

(b)

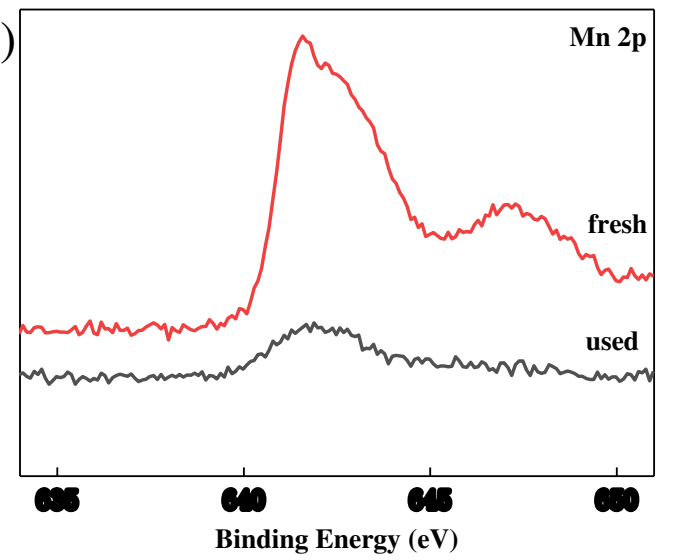

Fig. 8 XPS spectra of element before and after the reaction

(a) Fe element; (b) Mn element

On the basis of free radical identification and XPS analysis, a possible catalytic mechanism in the $\mathrm{Mn}-\mathrm{FeOCl} / \mathrm{PMS}$ system is proposed Fig. 9: $\mathrm{Fe}^{2+} / \mathrm{Fe}^{3+}$ and $\mathrm{Mn}^{2+} / \mathrm{Mn}^{3+}$ and other redox pairs distributed on the catalyst surface are in contact with PMS, and a variety of reactions occur (Eq. (11)-Eq. (16)) to accelerate the generation of free radicals. In addition, because $\mathrm{Mn}^{3+}$ is more oxidative than $\mathrm{Fe}^{3+}, \mathrm{Fe}^{2+}$ and $\mathrm{Mn}^{3+}$ can regenerate $\mathrm{Fe}^{3+}$ (Eq. (17)); it is worth noting that part of the $\mathrm{SO}_{4}{ }^{--}$can react with $\mathrm{OH}^{-}$to form $\mathrm{HO} \cdot\left(\mathrm{Eq} .(18)\right.$ ) and part of $\mathrm{HO} \cdot+\mathrm{SO}_{5}{ }^{-}$. will be converted into $\mathrm{SO}_{4} \cdot{ }^{-}$(Eq. (19)), which proves once again that ${ }^{\circ} \mathrm{OH}$ and $\mathrm{SO}_{4} \cdot{ }^{-}$are used to remove pollutants in the entire reaction process.

$$
\begin{aligned}
& \mathrm{Mn}^{2+}+\mathrm{HSO}_{5}^{-} \rightarrow \mathrm{Mn}^{3+}+\mathrm{SO}_{4}{ }^{2-}+\mathrm{HO} \cdot \\
& \mathrm{Mn}^{2+}+\mathrm{HSO}_{5}{ }^{-} \rightarrow \mathrm{OH}^{-}+\mathrm{Mn}^{3+}+\mathrm{SO}_{4}{ }^{-} \\
& \mathrm{Mn}^{3+}+\mathrm{HSO}_{5} \rightarrow \mathrm{H}^{+}+\mathrm{Mn}^{2+}+\mathrm{SO}_{5} \cdot- \\
& \mathrm{Fe}^{3+}+\mathrm{HSO}_{5}{ }^{-} \rightarrow \mathrm{H}^{+}+\mathrm{Fe}^{2+}+\mathrm{SO}_{5} \cdot{ }^{-} \\
& \mathrm{Fe}^{2+}+\mathrm{HSO}_{5} \rightarrow \mathrm{HO}+\mathrm{Fe}^{3+}+\mathrm{SO}_{4}{ }^{2-} \\
& \mathrm{Fe}^{2+}+\mathrm{HSO}_{5} \rightarrow \mathrm{OH}^{-}+\mathrm{Fe}^{3+}+\mathrm{SO}_{4} \cdot- \\
& \mathrm{Fe}^{2+}+\mathrm{Mn}^{3+} \rightarrow \mathrm{Mn}^{2+}+\mathrm{Fe}^{3+} \\
& \mathrm{SO}_{4}{ }^{-}+\mathrm{OH}^{-} \rightarrow \mathrm{SO}_{4}{ }^{2-}+\mathrm{HO} \text {. } \\
& 2 \mathrm{HO}+\mathrm{SO}_{5} \cdot{ }^{-} \rightarrow \mathrm{SO}_{4} \cdot{ }^{-}+\mathrm{H}_{2} \mathrm{O}+\mathrm{O}_{2}
\end{aligned}
$$




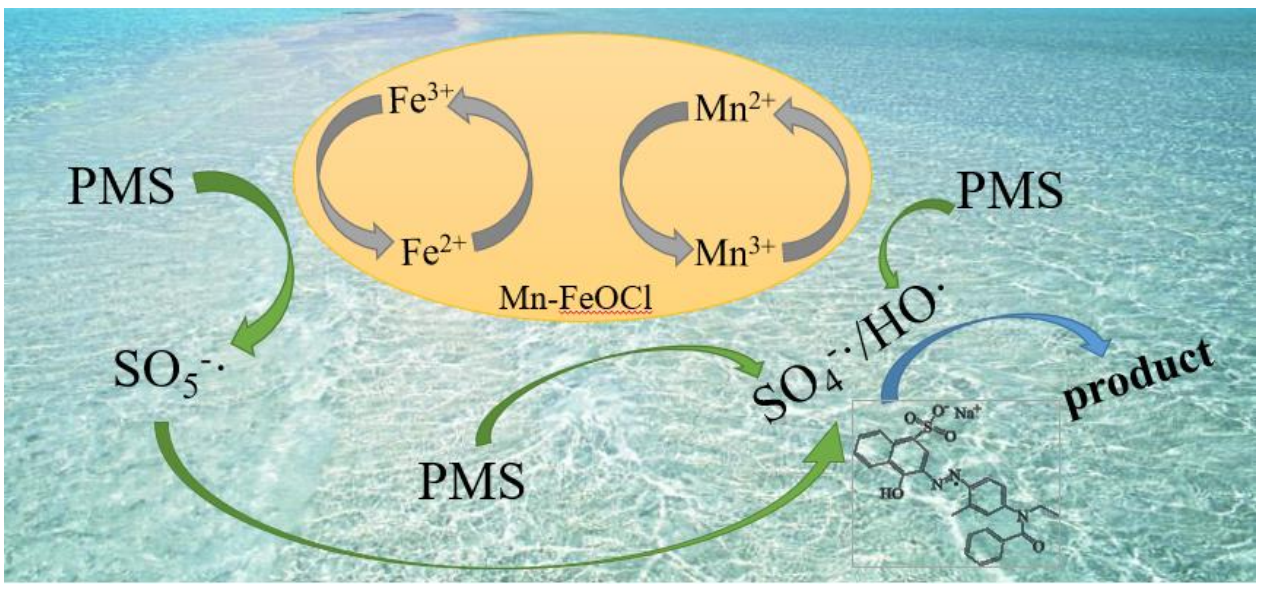

Fig. 9 Catalytic mechanism in Mn-FeOCl/PMS system

\section{Reusability of Mn-FeOCI}

In actual application, the reusability of the material is an important indicator to measure the performance of the catalyst. In order to evaluate the reusability of the $\mathrm{Mn}-\mathrm{FeOCl}$, the reacted material is centrifuged and cleaned and dried with deionized water and absolute ethanol and then used again. The ratio of reused catalyst after each reaction was presented in Fig. 10. In the degradation experiment of $\mathrm{ARB}$, the experimental conditions were kept unchanged, and the degradation rate reached $96.3 \%$ within 30 minutes during the second use; it dropped to $92.8 \%$ during the third time. It is speculated that the degradation of catalytic performance may be due to the adsorption of ARB degradation products on the surface after repeated use of the material, thereby reducing the active sites of activated PMS, resulting in a decrease in the reaction rate and affecting the catalytic effect.

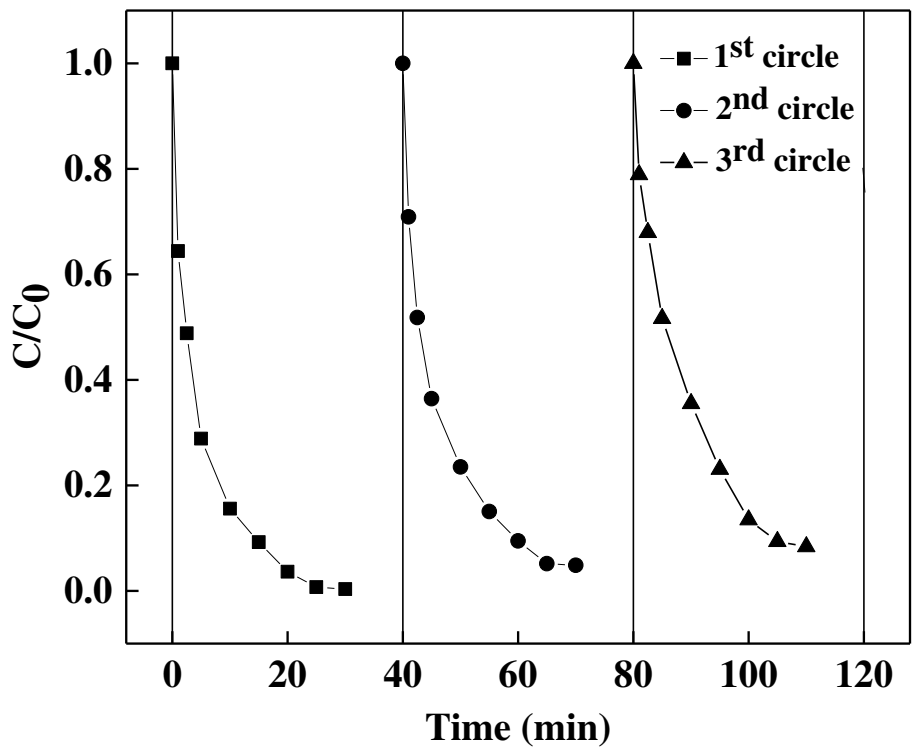

Fig.10. The effect of using reusable of $\mathrm{Mn}-\mathrm{FeOCl}$ on the degradation of $\mathrm{ARB}$ 
In order to further study the mineralization effect and reaction process of $\mathrm{Mn}-\mathrm{FeOCl} / \mathrm{PMS}$ system on ARB, UV-vis spectrum scanning and TOC test were carried out. Fig.11(a) shows the spectrum change process during the degradation of ARB. It can be seen that ARB has two main characteristic peaks at $310 \mathrm{~nm}$ and $515 \mathrm{~nm}$, corresponding to the naphthalene ring and the even single bond chromophore (Yang et al. 2004, Lan et al. 2015). With the progress of the reaction, the characteristic peak at $515 \mathrm{~nm}$ continued to decrease, indicating that the $\mathrm{Mn}-\mathrm{FeOCl} / \mathrm{PMS}$ system can oxidize the chromophoric groups in the ARB and has a good decolorization effect. With the continuous extension of the reaction, the characteristic peak of the naphthalene ring at $310 \mathrm{~nm}$ also continued to decrease, indicating that the reaction can further oxidize the intermediate products produced by the degradation of ARB, and has a certain mineralization ability.

Fig. 11(b) shows the ability of the system to mineralize ARB. The content of TOC dropped from $7.27 \mathrm{mg} / \mathrm{L}$ to $4.43 \mathrm{mg} / \mathrm{L}$ after 60 minutes of reaction; the removal rate was $42.5 \%$. Combining experimental results and related literature, it is speculated that the degradation process of ARB may be that the Mn-FeOCl/PMS system first oxidizes the chromophore and naphthalene ring of ARB, and then generates aromatic compounds mainly composed of benzene ring, and some intermediate products are further degraded into small Molecular organic matter is eventually mineralized into $\mathrm{CO}_{2}$ and $\mathrm{H}_{2} \mathrm{O}$.
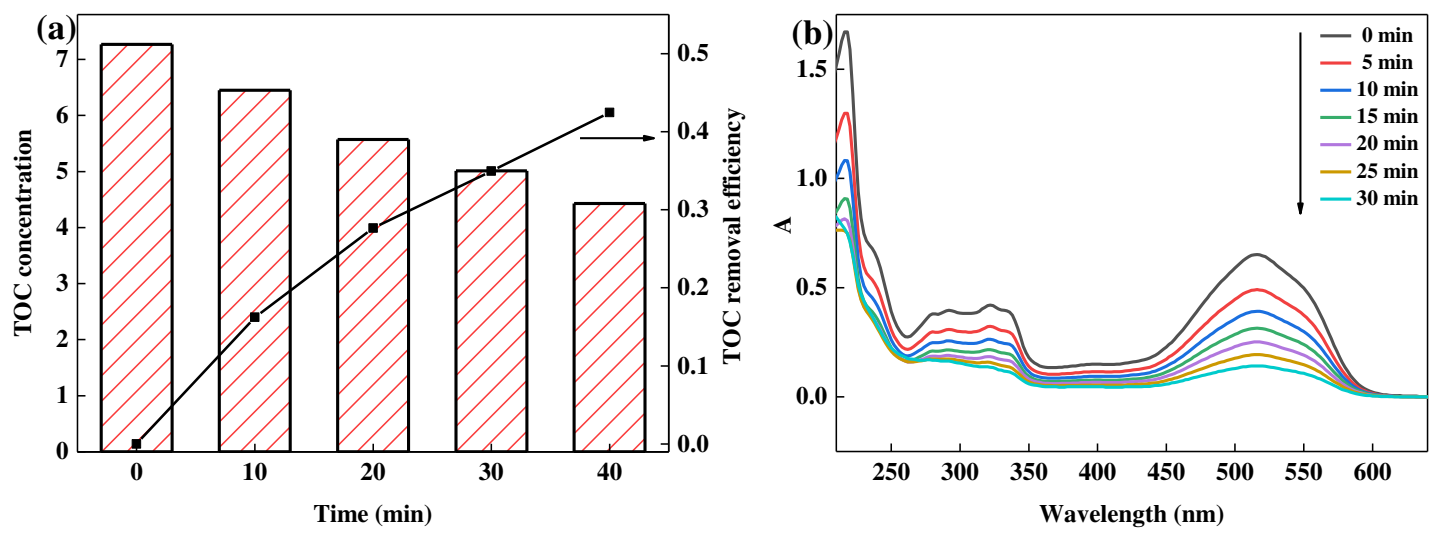

Fig. 11 (a) TOC degradation trend; (b) UV-visible spectrum changes during ARB degradation (Experimental conditions: initial ARB concentration $=0.05 \mathrm{mmol} / \mathrm{L}, \mathrm{Mn}-\mathrm{FeOCl}=0.10 \mathrm{~g} / \mathrm{L}, \mathrm{PMS}$ concentration $=1 \mathrm{mmol} / \mathrm{L}, \mathrm{pH}=7.0, \mathrm{~T}=25^{\circ} \mathrm{C}$ )

\section{Conclusion}

The $\mathrm{Mn}-\mathrm{FeOCl}$ material was successfully prepared by partial pyrolysis, which can effectively activate PMS to degrade the azo dye ARB, and has good decolorization effect and mineralization ability. In the $\mathrm{Mn}-\mathrm{FeOCl} / \mathrm{PMS}$ system, the degradation efficiency of ARB increases with the increase of the dosage of $\mathrm{Mn}-\mathrm{FeOCl}$, the dosage of PMS, the initial $\mathrm{pH}$ and the concentration of $\mathrm{Cl}^{-}$; $\mathrm{HA}$ versus $\mathrm{Mn}-\mathrm{FeOCl} / \mathrm{PMS}$ system versus ARB Degradation has an inhibitory effect. The MnFeOCl/PMS system has a better degradation effect on ARB under neutral and alkaline conditions. Through XPS analysis, the degradation mechanism is inferred. The reaction system produces both $\cdot \mathrm{OH}$ and $\mathrm{SO}_{4} \cdot{ }^{-}$, of which $\mathrm{SO}_{4} \cdot-$ is dominant. 
Acknowledgements My deepest gratitude goes first and foremost to professor Dan Zhao for her constant encouragement and guidance. I am indebted to professor Yan-mao Dong owing to his guidance in this manuscript. And I also thank other authers for their contributions to the manuscript.

Availability of data and materials The datasets used and/or analyzed during the current study are available from the corresponding author on reasonable request.

Author contribution All authors contributed to the study conception and design. Material preparation, data collection, and analysis were performed by Rong Chen and Chengrun Cai. The first draft of the manuscript was written by Rong Chen and checked by Yan Yuan and Yanmao Dong. the logic and grammar of the manuscript were examined by Dan Zhao and Zhili Li. All authors commented on previous versions of the manuscript. All authors read and approved the final manuscript.

Funding This work was supported by Suzhou Regional Water Quality Improvement and Water Ecological Security Technology and Comprehensive Demonstration Project (2017ZX07205) and Suzhou Industrialization Prospect Project (SYG201744).

\section{Declarations}

Ethics approval and consent to participate Not applicable.

Consent for publication Not applicable.

Competing interests The authors declare no competing interests.

\section{References}

Asam S, Chen J, Qu RJ, Afzal AD, May BJ, Ahmed AA, Wang ZY (2020) Degradation of sulfadimethoxine in phosphate buffer solution by UV alone, UV/PMS and $\mathrm{UV} / \mathrm{H}_{2} \mathrm{O}_{2}$ : Kinetics, degradation products, and reaction pathways. Chem Eng J 398: 125357

Buxton GV, Greenstock CL, Helman WP, Ross AB (1988) Critical Review of Rate Constants for Reactions of Hydrated Electrons, Hydrogen Atoms and Hydroxyl Radicals $\left(\cdot \mathrm{OH} / \mathrm{O}^{-}\right)$in Aqueous Solution. J Phys Chem Ref Data 17(2): 513-886

Cao Y, Cui KP, Chen YH, Cui MS, Li GH, Li D, Yang XJ (2021) Efficient degradation of tetracycline by $\mathrm{H}_{2} \mathrm{O}_{2}$ catalyzed by $\mathrm{FeOCl}$ : A wide range of $\mathrm{pH}$ values from 3 to 7. Solid State Sci 113: 106548

Cao YY, Ding JF, Xu JH (2021) Alumina abrasive wheel wear in ultrasonic vibration-assisted creepfeed grinding of Inconel 718 nickel-based superalloy. J Mater Process Technol 297:117241

Chen MD, Xu HM, Wang Q, Li DY, Xia DS (2018) Activation mechanism of sodium percarbonate by FeOCl under visible-light-enhanced catalytic oxidation. Chem Phys Lett 706: 415-420

Chen RX, Yin H, Peng H, Wei XP, Yu XL, Xie DP, Lu GN, Dang Z (2020) Removal of triphenyl phosphate by nanoscale zerovalent iron (nZVI) activated bisulfite: Performance, surface reaction mechanism and sulfate radical-mediated degradation pathway. Environ Pollut 260:113983. 
Chen YQ, Xie PC, Wang ZP, Shang R, Wang SL (2017) UV/persulfate preoxidation to improve coagulation efficiency of Microcystis aeruginosa. J Hazard Mater 322: 508-515

Dai YD, Yu Z, He Y, Huang HB, Shao T, Lin J, Ali AM, Jiang ZY, Hsia YF (2002) Mössbauer studies on the spiral antiferromagnetic coupling in iron oxychloride. Chem Phys Lett 358: 473-478

Ding RR, Li WQ, He CS, Wang YR, Liu XC, Zhou GN, Mu Y (2021) Oxygen vacancy on hollow sphere $\mathrm{CuFe}_{2} \mathrm{O}_{4}$ as an efficient Fenton-like catalysis for organic pollutant degradation over a wide $\mathrm{pH}$ range. Appl Catal B-Environ 291: 120069

Ding YB, Wang XR, Fu LB, Peng XQ, Pan C, Mao QH, Wang CJ, Yan JC (2021) Nonradicals induced degradation of organic pollutants by peroxydisulfate (PDS) and peroxymonosulfate (PMS): Recent advances and perspective. Sci Total Environ 765:142794

Ding YB, Zhu LH, Wang N, Tang HQ (2013) Sulfate radicals induced degradation of tetrabromobisphenol A with nanoscaled magnetic $\mathrm{CuFe}_{2} \mathrm{O}_{4}$ as a heterogeneous catalyst of peroxymonosulfate. Appl Catal B-Environ 129: 153-162

Do SH, Kwon YJ, Kong SH (2010) Effect of metal oxides on the reactivity of persulfate/Fe (II) in the remediation of diesel-contaminated soil and sand. J Hazard Mater 182: 933-936

Ghanavatkar CW, Mishra, VR, Sekar N (2021). Review of nlophoric azo dyes - developments in hyperpolarizabilities in last two decades. Dyes Pigments 191, 109367

Guan YH, Ma J, Li XC, Fang JY, Chen LW (2011) Influence of pH on the formation of sulfate and hydroxyl radicals in the UV/peroxymonosulfate system. Environ sci Technol 45: 9304-9314

Guan YH, Ma J, Ren YM, Liu YL, Xiao JY, Lin LQ, Zhang C (2013) Efficient degradation of atrazine by magnetic porous copper ferrite catalyzed peroxymonosulfate oxidation via the formation of hydroxyl and sulfate radicals. Water Rese 47: 5431-5438.

Hao FF, Guo WL, Wang AQ, Leng YQ, Li HL (2014) Intensification of sonochemical degradation of ammonium perfluorooctanoate by persulfate oxidant. Ultrason Sonochem 21:554-558

Huang M, Wang XL, Liu C, Fang GD, Gao J, Wang YJ, Zhou DM (2021) Mechanism of metal sulfides accelerating $\mathrm{Fe}(\mathrm{II}) / \mathrm{Fe}$ (III) redox cycling to enhance pollutant degradation by persulfate: Metallic active sites vs. reducing sulfur species. J Hazard Mater 404: 124175

Huang Y, Wang ZH, Liu QZ, Wang XX, Yuan ZJ, Liu JS (2017) Effects of chloride on PMS-based pollutant degradation: A substantial discrepancy between dyes and their common decomposition intermediate (phthalic acid). Chemosphere 187:338-346.

Jiang LL, Zhang L, Cui C, Zhang J, Liu GD, Song JJ (2019) Efficient degradation of phenol using $\mathrm{Sn}^{4+}$ doped $\mathrm{FeOCl}$ as photo-Fenton catalyst. Mater Lett 240: 30-34.

Lan HC, Wang AM, Liu RP, Liu HJ, Qu JH (2015) Heterogeneous photo-Fenton degradation of acid red B over $\mathrm{Fe}_{2} \mathrm{O}_{3}$ supported on activated carbon fiber. J Hazard Mater 285: 167-172.

Latifoglu A, Gurol MD (2003) The effect of humic acids on nitrobenzene oxidation by ozonation and $\mathrm{O}_{3} / \mathrm{UV}$ processes. Water Res 37:1879-1889.

Ma QL, Zhang XY, Guo RN, Zhang HX, Cheng QF, Xie MZ, Chen XW (2019) Persulfate activation by magnetic $\gamma-\mathrm{Fe}_{2} \mathrm{O}_{3} / \mathrm{Mn}_{3} \mathrm{O}_{4}$ nanocomposites for degradation of organic pollutants. Sep Purif Technol 210: 335-342

Malik R, Rana PS, Tomer VK, Chaudhary V, Nehra SP, Duhan S (2016) Nano gold supported on ordered mesoporous $\mathrm{WO}_{3} / \mathrm{SBA}-15$ hybrid nanocomposite for oxidative decolorization of azo dye. Microporous Mesoporous Mat 225: 245-254

Qu SY, Wang WH, Pan XY, Li CL (2020) Improving the Fenton catalytic performance of FeOCl using an electron mediator. J Hazard Mater 384: 121494 
Qu, SQ, Li, CL, Sun, X.S, Wang, JW, Luo HJ, Wang S, Ta JY, Li DY (2019). Enhancement of peroxymonosulfate activation and utilization efficiency via iron oxychloride nanosheets in visible light. Sep Purif Technolo 224: 132-141

Robinson T, Mcmullan G, Marchant R, Nigam P (2001) Remediation of dyes in textile effluent: a critical review on current treatment technologies with a proposed alternative. Bioresour Technol 77: 247-255

Sun M, Zucker I, Davenport DM, Zhou XC, Qu JH, Elimelech M (2018) Reactive, Self-Cleaning Ultrafiltration Membrane Functionalized with Iron Oxychloride Nanocatalysts. Environ Sci Technol 52(15): 8674-8683

Sun SB, Yao H, Fu WY, Liu F, Wang XW, Zhang W (2020) Enhanced degradation of carbamazepine in FeOCl based Photo-Fenton reaction. J Environ Chem Eng 9:104501.

Tan CQ, Gao NY, Deng Y, Deng J, Zhou SQ, Li J, Xin XY (2014) Radical induced degradation of acetaminophen with $\mathrm{Fe}_{3} \mathrm{O}_{4}$ magnetic nanoparticles as heterogeneous activator of peroxymonosulfate. J Hazard Mater 276: 452-460

Tan CQ, Sheng TY, Xu QL, Xu TH, Sun KC, Deng L, Xu W (2021) Cobalt doped iron oxychloride as efficient heterogeneous Fenton catalyst for degradation of paracetamol and phenacetin. Chemosphere 263: 127989

Tugba OH, Idil AA (2013) Comparison of sulfate and hydroxyl radical based advanced oxidation of phenol. Chem Eng J 224: 10-16

Wang GL, Chen S, Xie Q, Yu HT, Zhang YB (2017) Enhanced activation of peroxymonosulfate by nitrogen doped porous carbon for effective removal of organic pollutants. Carbon 115: 730739

Wang J, Jiang Z, Zhang ZH, Xie YP, Wang XF, Xing ZQ, Xu R, Zhang XD(2008)Sonocatalytic degradation of acid red $\mathrm{B}$ and rhodamine $\mathrm{B}$ catalyzed by nano-sized $\mathrm{ZnO}$ powder under ultrasonic irradiation. Ultrason Sonochem 15: 768-774.

Wang YX, Sun HQ, Ang HM, Tadé MO, Wang SB (2015) 3D-hierarchically structured $\mathrm{MnO}_{2}$ for catalytic oxidation of phenol solutions by activation of peroxymonosulfate: Structure dependence and mechanism. Appl Catal B-Environ 164: 159-167

Wang ZH, Yuan RX, Guo YG, Xu L, Liu JS (2011) Effects of chloride ions on bleaching of azo dyes by $\mathrm{Mn}^{2+}$ /oxone regent: Kinetic analysis. J Hazard Mater 190: 1083-1087.

Wei YF, Guo KX, Wu HH, Yuan P, Liu D, Du PX, Chen PC, Wei LM, Chen W (2021) Highly regenerative and efficient adsorption of phosphate by restructuring natural palygorskite clay via alkaline activation and co-calcination. Chem commun 57:1637-1642

Wordofa DN, Walker SL, Liu H (2017) Sulfate Radical-Induced Disinfection of Pathogenic Escherichia coli O157:H7 via Iron-Activated Persulfate. Environ Sci Technol Lett 4:154-160.

Xu L, Su JF, Huang TL, Li GQ, Ali A, Shi J (2021) Simultaneous removal of nitrate and diethyl phthalate using a novel sponge-based biocarrier combined modified walnut shell biochar with $\mathrm{Fe}_{3} \mathrm{O}_{4}$ in the immobilized bioreactor. J Hazard Mater 414:125578

$\mathrm{Xu} \mathrm{LJ}$, Chu W, Gan L (2015) Environmental application of graphene-based $\mathrm{CoFe}_{2} \mathrm{O}_{4}$ as an activator of peroxymonosulfate for the degradation of a plasticizer. Chem Eng J 263: 435-443

Xu LJ, Wang XT, Sun Y, Gong H, Guo MZ, Zhang XM, Meng L, Gan L (2020) Mechanistic study on the combination of ultrasound and peroxymonosulfate for the decomposition of endocrine disrupting compounds. Ultrason Sonochem 60: 104749

Yang XJ, Xu XM, Xu J Han YF (2013) Iron oxychloride (FeOCl): an efficient Fenton-like catalyst 
for producing hydroxyl radicals in degradation of organic contaminants. J Am Chem Soc135: 16058

Yang XJ, Xu XM, Xu XC, Xu J, Wang LH, Semiat R, Han YF (2016) Modeling and kinetics study of Bisphenol A(BPA) degradation over an $\mathrm{FeOCl} / \mathrm{SiO}_{2}$ Fenton-like catalyst. Catal Today 276: 85-96

Yang XK, Wang JQ, Wang TD (2004) Rate Constants for the Reactions of $\mathrm{NO}_{3}^{-}$.and $\mathrm{SO}_{4}^{-}$. Radicals with Oxalic Acid and Oxalate Anions in Aqueous Solution. Chin Chem Lett 05:583-586.

Yuan RX, Sadiqua N, Wang ZH, Liu JS (2011) Effects of chloride ion on degradation of Acid Orange 7 by sulfate radical-based advanced oxidation process: Implications for formation of chlorinated aromatic compounds. J Hazard Mater196:173-179

Zhang J, Yang MX, Ye L, Zhong ML, Sha JQ, Liu GD, Zhao XF, Liu SJ (2019) Ce e $^{3+}$ self-doped $\mathrm{CeOx} / \mathrm{FeOCl}$ : an efficient Fenton catalyst for phenol degradation under mild conditions. Dalton Trans, 48:3476-3485(10).

Zhang J, Zhao X, Zhong M (2018) FeOCl/rGO heterojunction with enhanced catalytic performance as a photo-Fenton catalyst. Ber Dtsch Chem Ges 42:1002.

Zhang WQ, Zhou SQ, Sun JL, Meng XY, Luo JM, Zhou DD (2018) Crittenden John. Impact of Chloride Ions on $\mathrm{UV} / \mathrm{H}_{2} \mathrm{O}_{2}$ and UV/Persulfate Advanced Oxidation Processes. Environ Sci Technol 52: 7380-7389

Zhao JZ, Ji MX, Di J, Zhang Y, He MQ, Li HM, Xia JX (2020) Novel Z-scheme heterogeneous photo-Fenton-like $\mathrm{g}-\mathrm{C}_{3} \mathrm{~N}_{4} / \mathrm{FeOCl}$ for the pollutants degradation under visible light irradiation. J Photochem Photobiol A-Chem 391: 112343

Zhu MH, Rocha T.C.R, Thomas LK, Axel KG (2016) Promotion Mechanisms of Iron Oxide-Based High Temperature Water-Gas Shift Catalysts by Chromium and Copper. Acs Catalysis 6: 4455-4464

Zou RS, Jin B, Zhang YF (2020) Feasibility and applicability of the scaling-up of bio-electro-Fenton system for textile wastewater treatment. Environ Int 134: 105352 